\title{
Limitation of life-sustaining treatment and patient involvement in decision-making: a retrospective study of a Danish COVID-19 patient cohort
}

Hanne Irene Jensen ${ }^{1,2,3^{*}} \mathbb{0}$, Sevim Ozden ${ }^{1}$, Gitte Schultz Kristensen ${ }^{4}$, Mihnaz Azizi ${ }^{5}$, Siri Aas Smedemark ${ }^{6}$ and Christian Backer Mogensen 3,4

\begin{abstract}
Background: The coronavirus (COVID-19) pandemic and the risk of an extensive overload of the healthcare systems have elucidated the need to make decisions on the level of life-sustaining treatment for patients requiring hospitalisation. The purpose of the study was to investigate the proportion and characteristics of COVID-19 patients with limitation of life-sustaining treatment decisions and the degree of patient involvement in the decisions.

Methods: A retrospective observational descriptive study was conducted in three Danish regional hospitals, looking at all patients $\geq 18$ years of age admitted in 2020 with COVID-19 as the primary diagnosis. Lists of hospitalised patients admitted due to COVID-19 were extracted. The data registration included age, gender, comorbidities, including mental state, body mass index, frailty, recent hospital admissions, COVID-19 life-sustaining treatment, ICU admission, decisions on limitations of life-sustaining treatment before and during current hospitalisation, hospital length of stay, and hospital mortality.

Results: A total of 476 patients were included. For 7\% (33/476), a decision about limitation of life-sustaining treatment had been made prior to hospital admission. At the time of admission, one or more limitations of life-sustaining treatment were registered for $16 \%$ (75/476) of patients. During the admission, limitation decisions were made for an additional 11 patients, totaling 18\% (86/476). For 40\% (34/86), the decisions were either made by or discussed with the patient. The decisions not made by patients were made by physicians. For 36\% (31/86), no information was disclosed about patient involvement.

Conclusions: Life-sustaining treatment limitation decisions were made for 18\% of a COVID-19 patient cohort. Hereof, more than a third of the decisions had been made before hospital admission. Many records lacked information on patient involvement in the decisions.
\end{abstract}

Keywords: End-of-life, Patient involvement, Life-sustaining treatment, COVID-19, Shared decision-making

\footnotetext{
*Correspondence: hanne.irene.jensen@rsyd.dk

${ }^{1}$ Department of Anaesthesiology and Intensive Care, Kolding Hospital, University Hospital of Southern Denmark, Sygehusvej 24, 6000 Kolding, Denmark

Full list of author information is available at the end of the article
}

\section{Background}

The coronavirus (COVID-19) pandemic and the risk of an extensive strain of the healthcare systems have made it clear that there is a need to make decisions on the level of life-sustaining treatment for patients requiring hospitalisation, including which patients should be original author(s) and the source, provide a link to the Creative Commons licence, and indicate if changes were made. The images or other third party material in this article are included in the article's Creative Commons licence, unless indicated otherwise in a credit line to the material. If material is not included in the article's Creative Commons licence and your intended use is not permitted by statutory regulation or exceeds the permitted use, you will need to obtain permission directly from the copyright holder. To view a copy of this licence, visit http://creativecommons.org/licenses/by/4.0/. The Creative Commons Public Domain Dedication waiver (http://creativeco mmons.org/publicdomain/zero/1.0/) applies to the data made available in this article, unless otherwise stated in a credit line to the data. 
offered care in an intensive care unit (ICU). Patients with advanced illnesses, frailty and old age are more likely to develop severe symptoms of COVID-19 and death [1, 2], and the chance of a successful outcome from ICU therapy may be minimal $[3,4]$. If this is the case, transfer to an ICU should be carefully considered for these patients. For patients where ICU therapy is assessed as potentially beneficial, it is important to ensure that this therapy is in accordance with the patient's wishes regarding life-sustaining treatment [2].

Studies examining end-of-life (EOL) practices have shown that patients' wishes of the level of life-sustaining treatment are often unknown [5, 6]. A Canadian study surveyed the wishes for the level of life-sustaining treatment of medical patients primarily above 80 years of age, and only $30 \%$ were documented in the medical records [7]. Unawareness of patients' wishes may lead to inappropriate treatment [8-11], but in acute hospitalisation or acute worsening of the patient's condition during hospitalisation, there may not be the time or option to obtain the patient's wishes. Therefore, conversations about values and preferences for life-sustaining treatment should occur in a stable period of the illness trajectory whenever possible [12, 13]. As the pandemic has highlighted the need for goal-concordant care [2], it is of interest to examine how EOL practice and limitation decisions are executed in a population of hospitalised patients with COVID-19 to improve our efforts in these critical decisions.

Therefore, the study aimed to investigate the proportion and characteristics of COVID-19 patients with limitation of life-sustaining treatment decisions and the degree of patient involvement in the decisions.

\section{Methods}

\section{Population and settings}

All patients $\geq 18$ years of age with COVID-19 as the primary diagnosis admitted to one of three Danish regional university hospitals in 2020. The hospitals have 1296 beds (356, 370, and 570, respectively) and cover most medical specialities. The three hospitals provide all treatments for COVID-19 except Extra Corporeal Membrane Oxygenation (ECMO). None of the hospitals had high-dependency units. At the COVID-19 wards, oxygen treatment was possible as basic treatment with catheter or reservoir mask and as High Flow. One of the hospitals also provided Continuous Positive Airway Pressure (CPAP) treatment at the ward. For all three hospitals, COVID-19 patients in need of non-invasive ventilation (NIV) were transferred to the ICU. The hospitals' COVID-19 guidelines require that a patient's level of life-sustaining treatment is assessed upon admission [14].

\section{Conditions}

According to Danish legislation, a patient can decline life-sustaining treatment but cannot demand treatment such as ICU therapy or cardiopulmonary resuscitation (CPR) if this is assessed as futile by the treating physicians. However, if possible, limitation decisions should be discussed with the patient. Furthermore, relatives do not have the legal right to decide on behalf of patients without decision-making capacity. If a patient's wishes are unknown, the decision regarding the level of life-sustaining treatment is the physicians' responsibility $[15,16]$.

\section{Main outcomes}

The primary outcomes were the proportion of patients admitted with COVID-19 and a hospital record documented decision concerning the limitation of life-sustaining treatment before or during admission. Secondary outcomes were the level of patient involvement in the decision-making and characteristics of patients with limitation of life-sustaining treatment decisions.

\section{Data registration}

Lists of all hospitalised patients admitted in 2020 due to COVID-19 were extracted from each hospital's patient registration system. The registration database included data on age, gender, comorbidities including mental state, body mass index (BMI), frailty assessed by Clinical Frailty Scale [17], number of hospital admissions within the last year, COVID-19 treatment, admission to the ICU, decisions on limitations of life-sustaining treatment (do-notresuscitate, do not transfer to an intensive care unit, and do-not-intubate) before and during current hospitalisation and how the patients were involved, hospital length of stay, and hospital mortality. The authors developed the database based on literature and former research, and the database was pilot tested on the first ten patients from one of the hospitals to secure that the registration options were exclusive and exhaustive. Questions arising during the data registration, both pilot and later on, were discussed and decided upon within the research group. One researcher from each hospital manually reviewed their admitted COVID-19 patients' hospital records (all content) and documented the data in the database. Only data from one admission (including transfer to another hospital) was documented in the database. For patients admitted more than once due to COVID-19 in the study timeframe, their most prolonged admission was included. If a patient was transferred to another hospital for specialised COVID treatment, the transfer was included in the registration. Patients who tested positive for COVID-19 during a hospital stay but did not develop 
any symptoms of COVID-19 or where COVID-19 symptoms had no impact on the illness trajectory were not included in the study.

\section{Data analyses}

All patients with COVID-19 as the main diagnosis admitted to one of the three hospitals in 2020 were included, ensuring a broad COVID-19 population. As the first COVID-19 patients were admitted in March 2020, the actual inclusion time is from March 1st to December 31st 2020. The database was closed 70 days after January 1 st 2021. Patients still hospitalised were included with data until the closing of the database. As older patients more often suffer from advanced illnesses and frailty and are the most likely to develop severe symptoms of COVID19 and death compared to younger patients, sub-analyses were made for patients 70 years or older. Data are presented with descriptive statistics with $\mathrm{n}(\%)$ for proportions and median/interquartile range (IQR) for ordinal and non-normal distributed continuous variables. Fischer's exact test and Mann-Whitney U-test were used for comparing patients $<70$ years, and patients 70 years or older. The Chi-square test was used to explore associations between patient characteristics and limitation of life-sustaining treatment. All data were analysed in the statistical program Stata 15. A two-sided $p$ value $<0.05$ was considered significant.

\section{Results}

A total of 476 patients were included in the study, 138 from hospital A, 138 from hospital B, and 200 from hospital C. Of the total number of patients, $24 \%$ were admitted in March and April 2020, 3\% in May-June, 1\% in July-August, 17\% in September and October, and 36\% in November-December. Hospital length of stay (LOS) was a median of 6 days (interquartile range (IQR) 3-10 days; range $0-101$ days). For patients less than 70 years of age, LOS was a median of 5 days (IQR 2-8 days), and for patients 70 years or more, LOS was median 8 days (IQR 5-15 days).

Most of the patients had comorbidities, lived at home and had no home care. Patients 70 years or older were characterised by multiple comorbidities, established home care and often required mobility aids compared with those under 70 years (Table 1). The patient characteristics differed between the three hospitals in gender, age, number of comorbidities, living conditions, frailty and walking function (Additional file 1: Table S1).

The majority of patients received oxygen therapy and were discharged to home (Additional file 1: Table S2). The hospital mortality rate was 4\% (19/476); $2 \%$ $(5 / 258)$ for patients $<70$ years of age, and $6 \%(14 / 218)$ for patients aged 70 years or older. Additionally, eight patients (2\%) had life-sustaining treatment withdrawn and were discharged to be allowed to die at home.

From March 2020 to February 2021, 263 nursing home residents in the hospitals' region were infected with COVID-19, of which 73 died of the infection [18]. The three hospitals in the present study cover $57 \%$ of all nursing home residents in the region [19]. Our study included 21 nursing home residents admitted to hospital due to infection with COVID-19. This indicates that some COVID-19 infected nursing home residents were not hospitalised.

\section{Limitation of life-sustaining treatment}

As shown in Fig. 1 decisions about limitation of lifesustaining treatment were made prior to admission, at admission, and during the admission. A decision was made for $18 \%$ of patients, the most common being limitation to the ward. In 19\% hereof, it was documented that the patient made the decision, and for additionally $21 \%$, that the decision was discussed with the patients. For $36 \%$, no information was disclosed about patient involvement. Almost all of the limitation decisions were made for patients aged 70 years or older (Table 2).

For 43\% (203/476) of hospital records, no specific information about the level of life-sustaining treatment was provided at admission: in 53\% (137/258) for patients $<70$ years, and $30 \%(66 / 218)$ for patients 70 years or older).

For many of the patients, full treatment was an implicit order, as it was not documented as such in the hospital records, but was based on the treatment offered. For the whole "Full treatment group" $(\mathrm{n}=390)$, $3 \%$ of the hospital records included registration of discussion with the patient about the level of life-sustaining treatment.

The percentage of patients with limitation decisions decreased from March-August $(41 / 131 ; 31 \%)$ to September-December $(45 / 345 ; 13 \%) \quad(p<0.001)$. For patients with limitation decisions, a significantly larger number of patients admitted from September to December $(12 / 45 ; 27 \%)$ made the decision compared to patients admitted from March-August $(4 / 41 ; 10 \%)$ $(p=0.044)$.

In the whole period, no triage due to lack of ICU beds was needed.

\section{Factors associated with limitations}

Age, number of comorbidities, level of frailty, need for walking aids and living conditions were the main variables associated with decisions of treatment limitations (Table 3). 
Table 1 Patient characteristics

\begin{tabular}{|c|c|c|c|c|}
\hline & Total $n=476^{a}$ & Age $<70 n=258^{a}$ & Age $70+n=218^{a}$ & $p$ values ${ }^{b}$ \\
\hline Gender. Female n (\%) & $208(44)$ & $124(48)$ & $84(39)$ & 0.04 \\
\hline Age. Median (IQR) & $68(57-79)$ & $55(45-61)$ & $79(74-83)$ & \\
\hline BMI. Median (IQR) & $28(24-32)$ & $30(25-33)$ & $26(23-30)$ & $<0.001$ \\
\hline \multicolumn{5}{|l|}{ Comorbidities $^{\complement} \mathrm{n}(\%)$} \\
\hline None & $102(21)$ & $94(36)$ & $8(4)$ & \\
\hline Diabetes & $89(19)$ & $41(16)$ & $48(22)$ & \\
\hline Heart diseases ${ }^{d}$ & $359(75)$ & $94(36)$ & $265(122)$ & \\
\hline Lung diseases $^{e}$ & $102(21)$ & $42(16)$ & $60(28)$ & \\
\hline Cancer & $43(9)$ & $15(6)$ & $28(13)$ & \\
\hline Dementia & $20(4)$ & $0(0)$ & $20(9)$ & \\
\hline Other & $314(66)$ & $139(54)$ & $182(83)$ & \\
\hline Number of comorbidities. Median (IQR) & $2(1-3)$ & $1(0-2)$ & $3(1-4)$ & $<0.001$ \\
\hline $\begin{array}{l}\text { Number of admissions within last year Median } \\
\text { (IQR) }\end{array}$ & $0(0-1)$ & $0(0-0)$ & $0(0-1)$ & $<0.001$ \\
\hline Living conditions. n (\%) & & & & $<0.001$ \\
\hline Lives at home alone & $119(25)$ & $51(20)$ & $68(31)$ & \\
\hline Lives at home with others & $304(64)$ & $187(72)$ & $117(54)$ & \\
\hline Lives in care facility & $22(5)$ & $1(0.5)$ & $21(10)$ & \\
\hline Other & $18(4)$ & $9(3)$ & $9(4)$ & \\
\hline \multicolumn{5}{|l|}{ Home carec.n (\%) } \\
\hline None & $365(77)$ & $239(93)$ & $126(58)$ & \\
\hline Help with cleaning & $60(13)$ & $10(4)$ & $50(23)$ & \\
\hline Help with medicine & $61(13)$ & $11(4)$ & $50(23)$ & \\
\hline Help with personal hygiene & $51(11)$ & $8(3)$ & $43(20)$ & \\
\hline Help with food & $32(7)$ & $4(2)$ & $28(13)$ & \\
\hline Other & $35(7)$ & $5(2)$ & $30(14)$ & \\
\hline Clinical frailty scalef. Median (IQR) & $2(2-4)$ & $2(1-3)$ & $3(2-5)$ & $<0.001$ \\
\hline \multicolumn{5}{|l|}{ Walking function. n (\%) } \\
\hline Walks without aids & $371(78)$ & $240(93)$ & $131(60)$ & $<0.001$ \\
\hline Walks with walking stick & $14(3)$ & $4(2)$ & $10(5)$ & \\
\hline Walks with zimmer frame & $56(12)$ & $6(2)$ & $50(23)$ & \\
\hline Other walking aids & $12(3)$ & $2(1)$ & $10(4)$ & \\
\hline No walking function & $10(2)$ & $1(0.5)$ & $9(4)$ & \\
\hline
\end{tabular}

${ }^{a}$ Different $\mathrm{n}$ for individual variables due to missing data

${ }^{b}$ Fischer's exact test for categorical data and Mann-Whitney U-test for ordinal and continuous, non-normal distributed data

' Possible to choose more than one answer

${ }^{d}$ Hypertension, Ischemic heart disease, heart failure, AFLI. Percentage may be $>100$ due to some patients having more than one heart disease

e Chronic obstructive pulmonary disease, Asthma

${ }^{f}$ Clinical frailty scale: 1:Very fit; 2:Well; 3:Managing well; 4:Vulnerable; 5:Mildly Frail; 6: Moderately frail; 7:Severly frail; 8:Very severely frail; 9:Terminally ill

\section{Discussion}

In these Danish COVID-19 patients, one or more limitations of treatment were documented for $18 \%$ of the patients, and of those, $19 \%$ of the decisions were documented as made by the patient. In the group of patients where limitation of life-sustaining treatment were documented, less than half of the cases were discussed with the patient. A high number of the patient records lacked specific instructions about the level of life-sustaining treatment, despite the fact that all hospitals' COVID-19 guidelines required that the level of life-sustaining treatment was assessed upon admission.

The high number of hospital records where the level of life-sustaining treatment was not specified could cause uncertainty in a medical crisis. Danish legislation states that if a do-not-resuscitate order has not been documented, CPR must be initiated $[15,16]$. If the level of lifesustaining treatment has not been assessed and decided 


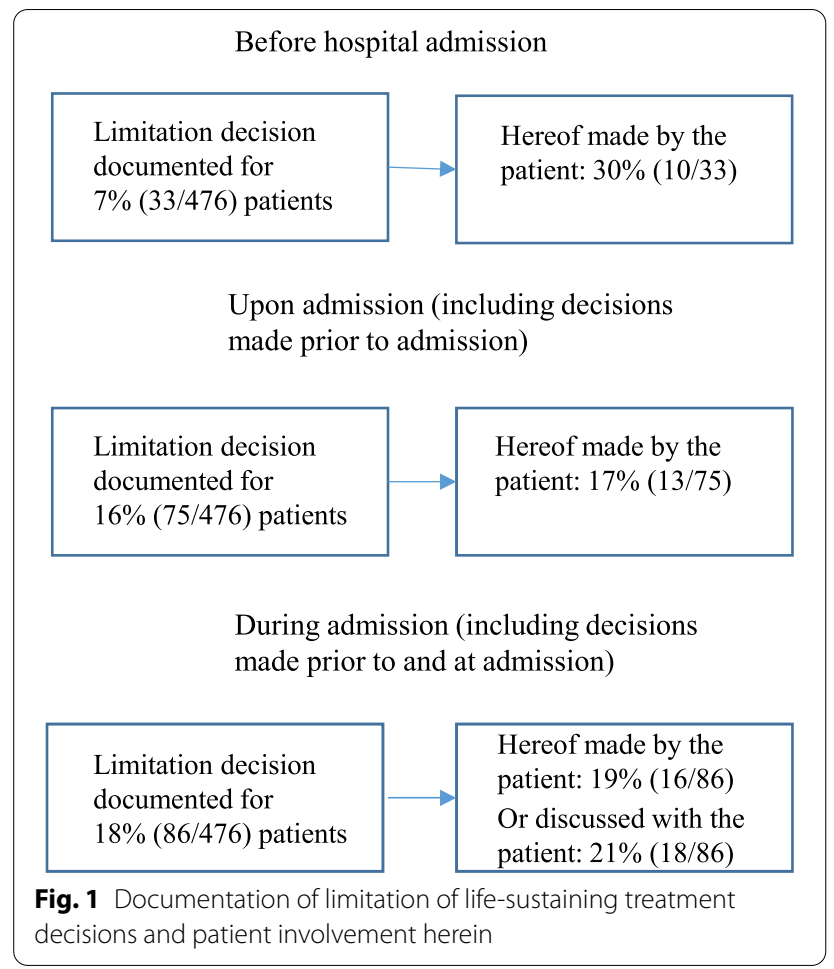

Fig. 1 Documentation of limitation of life-sustaining treatment decisions and patient involvement herein upon ahead of time, this may lead to inappropriate care $[10,20]$ and moral distress for healthcare professionals [21]. Conversations about life-sustaining treatments can lead to less aggressive EOL care [12, 13, 22], reduce health care costs [23], and may even lead to more prolonged survival [24]. Studies have shown that many patients have thought about life-sustaining treatment and EOL care, but less than a third have discussed their preferences with physicians $[7,25]$. Physicians may be afraid of distressing patients by bringing up the issue of life-sustaining treatment and death [26]. However, studies have shown no differences in the level of fear and anxiety in a group of terminally ill cancer patients, who discussed EOL, compared to a group that did not discuss EOL matters [27], and families were more uncomfortable than the patient talking about advanced care planning [28]. Finding the most appropriate time to conduct a conversation about patients' values and preferences for life-sustaining treatment may be challenging. Even though these conversations need not be lengthy [29], an acute care setting is often not ideal for either the patient or the healthcare professional [30]. In the current study, almost a third of the treatment limitation decisions upon admission were made before the admission. Conducting the conversation in a stable period in the patient's illness trajectory with a physician who knows the patients is preferred [26, 31]. Another issue is identifying patients with whom a

Table 2 Level of life-sustaining treatment during hospital admission

\begin{tabular}{|c|c|c|c|c|c|c|}
\hline & \multicolumn{2}{|l|}{ Total } & \multicolumn{2}{|l|}{ Age $<70$} & \multicolumn{2}{|c|}{ Age $70+$} \\
\hline & $n=476$ & $\%$ & $n=258$ & $\%$ & $n=218$ & $\%$ \\
\hline \multicolumn{7}{|l|}{ Level of life-sustaining treatment } \\
\hline Full treatment ${ }^{\mathrm{a}}$ & 390 & (88) & 252 & (98) & 138 & (63) \\
\hline ICU with MV but no CPR & 8 & (2) & 1 & $(0.5)$ & 7 & (3) \\
\hline No escalation to the ICU ${ }^{b}$ & 60 & (13) & 4 & (2) & 56 & (26) \\
\hline \multirow[t]{3}{*}{ Palliation only } & 18 & (4) & 1 & $(0.5)$ & 17 & (8) \\
\hline & \multicolumn{2}{|l|}{ Total } & \multicolumn{2}{|l|}{ Age $<70$} & \multicolumn{2}{|c|}{ Age $70+$} \\
\hline & $\mathrm{n}=86$ & $\%$ & $\mathrm{n}=6$ & $\%$ & $\mathrm{n}=\mathbf{8 0}$ & $\%$ \\
\hline \multicolumn{7}{|l|}{ Patients with limitation } \\
\hline \multicolumn{7}{|l|}{ Decision-maker } \\
\hline Physician & 70 & (81) & 5 & (83) & 65 & (81) \\
\hline Patient & 16 & (19) & 1 & $(17)$ & 15 & (19) \\
\hline \multicolumn{7}{|l|}{ Decision discussed with patient } \\
\hline Yes, patient made decision & 16 & (19) & 1 & $(17)$ & 15 & (19) \\
\hline Yes & 18 & (21) & 3 & (50) & 15 & (19) \\
\hline Not possible & 21 & (24) & 1 & (17) & 20 & (25) \\
\hline Not disclosed & 31 & (36) & 1 & (17) & 30 & (38) \\
\hline
\end{tabular}

ICU intensive care unit, $M V$ mechanical ventilation, $C P R$ cardiopulmonary resuscitation

a Includes both patients where "Full treatment" is ordered in the hospital record and those where no limitations are described or initiated

${ }^{b}$ Including no CPR 
Table 3 Factors associated with one or more limitations of treatment

\begin{tabular}{|c|c|c|c|c|c|}
\hline & \multicolumn{2}{|c|}{$\begin{array}{l}\text { Limitations. } \\
\text { Yes }\end{array}$} & \multicolumn{2}{|c|}{ Limitations. No } & \multirow[t]{2}{*}{$p$ value $^{c}$} \\
\hline & $\mathrm{n}=86^{\mathrm{a}}$ & $\%$ & $\mathrm{n}=363^{\mathrm{a}, \mathrm{b}}$ & $\%$ & \\
\hline \multicolumn{6}{|l|}{ Gender } \\
\hline Female & 31 & (36) & 162 & (45) & \multirow[t]{2}{*}{0.15} \\
\hline Male & 55 & (64) & 201 & (55) & \\
\hline \multicolumn{6}{|l|}{ Age } \\
\hline$<70$ years & 6 & (7) & 232 & (64) & \multirow[t]{2}{*}{$<0.001$} \\
\hline 70+ years & 80 & (93) & 131 & (36) & \\
\hline \multicolumn{6}{|l|}{$\mathrm{BMI}^{\mathrm{d}}$} \\
\hline$<18.5$ & 5 & (7) & 3 & (1) & \multirow[t]{4}{*}{0.007} \\
\hline $18.5-25$ & 30 & (43) & 75 & (32) & \\
\hline$>25-30$ & 19 & (28) & 73 & (31) & \\
\hline$>30$ & 15 & (22) & 81 & (34) & \\
\hline \multicolumn{6}{|l|}{ Comorbidities } \\
\hline None & 0 & (0) & 58 & (25) & \multirow[t]{4}{*}{$<0.001$} \\
\hline One comorbidity & 7 & (14) & 63 & (27) & \\
\hline Two comorbidities & 17 & (33) & 78 & (33) & \\
\hline$>$ Two comorbidities & 27 & (53) & 37 & (16) & \\
\hline \multicolumn{6}{|l|}{ Clinical frailty scale $e^{e}$} \\
\hline $1-2$ & 3 & (4) & 285 & (90) & \multirow[t]{3}{*}{$<0.001$} \\
\hline $3-5$ & 49 & (65) & 27 & (9) & \\
\hline $6-9$ & 24 & (32) & 4 & (1) & \\
\hline \multicolumn{6}{|l|}{ Walking function } \\
\hline No aids & 17 & (20) & 332 & (94) & \multirow[t]{3}{*}{$<0.001$} \\
\hline Walk with aid & 58 & (69) & 19 & (5) & \\
\hline No walking function & 9 & (11) & 1 & $(0.5)$ & \\
\hline \multicolumn{6}{|l|}{ Living conditions } \\
\hline Live at home $e^{f}$ & 59 & (69) & 339 & (97) & \multirow[t]{3}{*}{$<0.001$} \\
\hline Live in care facilities & 18 & (21) & 3 & (1) & \\
\hline Other & 8 & (9) & 9 & (3) & \\
\hline
\end{tabular}

${ }^{a}$ Different $\mathrm{n}$ in individual variables due to missing data

${ }^{b}$ Twenty-seven of 390 patients were excluded from the analysis due to lack of disclosure of the level of life-sustaining treatment

${ }^{c}$ Chi-square test

d Body mass index

e Clinical frailty scale: 1:Very fit; 2:Well; 3:Managing well; 4:Vulnerable; 5:Mildly Frail; 6: Moderately frail; 7:Severly frail; 8:Very severely frail; 9:Terminally ill

${ }^{f}$ Alone or with someone

conversation about wishes for life-sustaining treatment is pertinent [32, 33]. The "surprise question" (would I be surprised if this patient died in the next 12 months) is a poor to modest predictive tool for death [34], but may still be useful for timing a conversation for levels of treatment. A more specific tool is the Supportive and Palliative Care Indicators Tool (SPICT) which is a practical, clinical tool to help healthcare professionals identify patients at risk of deteriorating and dying [35].
Different models to clarify patients' wishes and preferences exist such as the British Recommended Summary Plan for Emergency Care and Treatment (ReSPECT) [36], the American Physician Orders for Life Sustaining Treatment (POLST) [37], and a variety of other advanced care planning tools [38]. Clarifying patients' wishes is possible also in an epidemic. In a retrospective analysis of routinely collected data from ReSPECT records in 2019 compared to April 2020, Hurlow et al. found an increased use of the ReSPECT form during the first part of the pandemic with a greater proportion of plans discussed with the patient compared to 2019 [39].

Although Danish family members do not have legal rights to make decisions on behalf of the patient without decision-making capacity, family members are involved as the patient's advocate in presenting the patient's values and preferences. However, several studies have shown discrepancies between patients' and families opinions [40], and therefore discussions with old, sick and frail patients about values, wishes, and preferences should be conducted in a stable disease period whenever possible.

The number of hospital records in the current study lacking information about patient involvement in a limitation decision may indicate that some decisions have been made without involving the patients. ICU therapy and CPR should only be offered to patients with a realistic hope of success, which is an assessment and decision made by physicians in Denmark, but this should be discussed with the patient. In the current study, limitation decisions were made for $37 \%$ of the patients 70 or more years of age. The whole group of patients aged 70 years or older had a median of three comorbidities and a median clinical frailty score of three. It would have been relevant to have had conversations about values and preferences with more patients from this group, as research has shown discordance between physicians' assessment of patient goal of care with the patients' own goals of care [41]. The current study aimed to explore the levels of limitation decisions and shared decision-making, but in future studies, it will be relevant to include patient involvement in decisions about full treatment, including transfer to an ICU.

The decrease in percentage of limitation decisions from the first part of the registration period compared to the last part of the period may partly be due to improved treatment options and experiences of treating COVID-19 patients [42]. The authors assess that limitation decisions for COVID-19 patients were made on identical foundation as other patients, and that the COVID-19 patients were offered treatment to similar extents as patients admitted with severe pneumonia.

Patient involvement, including shared decisionmaking, has become a key topic in healthcare, and 
this also includes patient involvement (if possible) in decisions regarding the level of life-sustaining treatment. However, this warrants an individual approach to ensure that the level of involvement is in accordance with the patient's wishes $[43,44]$. The results from this study present current practice and will hopefully promote further interest in patient involvement in shared decision-making about the level of life-sustaining treatment.

Strengths of the study include data from three hospitals and an entire 2020 cohort. Limitations include the retrospective access to hospital record data, which may result in information bias, especially in regard to lack of information about circumstances for decision-making and lack of documentation of patient involvement. Comorbidities were not weighted according to severity, and the Clinical Frailty Score was based solely on hospital record data without a clinical assessment. Likewise, the retrospective design prevents the possibility of assessing whether discussing a limitation decision with a patient was a possibility. There is probably collinearity in the factors found to be associated with limitations of treatment. However, due to the fairly limited number of patients with limitations included in the study, only unilineal analyses were performed. Apart from data on COVID-19 related nursing home deaths, no information was available on COVID-19 positive patients not admitted to the hospitals. Although a pilot registration was conducted and interpretation issues were discussed continuously in the research group, some subjectivity may exist in the manual review method. The study was conducted in Denmark where the legal frame for decision-making is different from for example the United States in regard to family involvement in decision-making. However, the need for timely conversations with patients with decision-making capacity regarding values and preferences and documentation hereof are relevant for all health professionals around the world.

\section{Conclusion}

Treatment limitation decisions were made for approximately a fifth of the COVID-19 patients. Of these patients, more than a third of the decisions had been made before hospital admission. Approximately half of the patients either made the treatment limitation decision themselves or were involved in the decision. However, many hospital records lacked information about level of life-sustaining treatment and patient involvement. The study underlines the need for a pro-active approach to clarification of patients' values, goals, and preferences for level of life-sustaining treatment and the need for a more extensive documentation of decision-making.

\section{Supplementary Information}

The online version contains supplementary material available at https://doi. org/10.1186/s13049-021-00984-1.

Additional file 1. Table S1. Patient characteristics divided between hospitals and Table S2. Treatment and discharge data.

\section{Authors' contributions}

All authors participated in designing the study; SO, GSK and MA extracted journal data; HIJ was responsible for data analyses and drafting of the manuscript. All authors critically revised the manuscript and approved the final version.

Funding

The study was funded by the Mads Clausen Foundation.

\section{Availability of data and materials}

The dataset used and analysed during the current study are available from the corresponding author on reasonable request.

\section{Declarations}

\section{Ethics approval and consent to participate}

According to Danish regulatory guidelines, permission to access the hospital records without patient consent were obtained from each hospital. The project was registered with the Danish Data Protection Agency (20/1316). According to Danish legislation, the study did not need permission from The Regional Committees on Health Research Ethics. All data were entered into a secure SurveyXact database, and code lists identifying registered patients were stored in a secure SharePoint research site.

\section{Consent for publication}

Not applicable.

\section{Competing interests}

The authors declare that they have no competing interests.

\section{Author details}

${ }^{1}$ Department of Anaesthesiology and Intensive Care, Kolding Hospital, University Hospital of Southern Denmark, Sygehusvej 24, 6000 Kolding, Denmark. ${ }^{2}$ Department of Anaesthesiology and Intensive Care, Vejle Hospital, University Hospital of Southern Denmark, Vejle, Denmark. ${ }^{3}$ Department of Regional Health Research, University of Southern Denmark, Odense, Denmark. ${ }^{4}$ Department of Emergency, Hospital Sønderjylland, University Hospital of Southern Denmark, Aabenraa, Denmark. ${ }^{5}$ Emergency Medicine, Hospital of South West Jutland, University Hospital of Southern Denmark, Esbjerg, Denmark. ${ }^{6}$ Department of Geriatric Medicine, Kolding Hospital, University Hospital of Southern Denmark, Kolding, Denmark.

Received: 13 October 2021 Accepted: 29 November 2021 Published online: 20 December 2021

\section{References}

1. Aly MH, Rahman SS, Ahmed WA, Alghamedi MH, Al Shehri AA, Alkalkami AM, Hassan $\mathrm{MH}$. Indicators of critical illness and predictors of mortality in COVID-19 patients. Infect Drug Resist. 2020;13:1995-2000.

2. Curtis JR, Kross EK, Stapleton RD. The importance of addressing advance care planning and decisions about do-not-resuscitate orders during novel coronavirus 2019 (COVID-19). JAMA. 2020:323(18):1771-2.

3. Guidet B, Leblanc G, Simon T, Woimant M, Quenot JP, Ganansia O, et al. Effect of systematic intensive care unit triage on long-term mortality among critically ill elderly patients in France: a randomized clinical trial. JAMA. 2017:318(15):1450-9.

4. Reignier J, Feral-Pierssens AL, Boulain T, Carpentier F, le Borgne P, Del Nista $D$, et al. Withholding and withdrawing life-support in adults in emergency care: joint position paper from the French Intensive Care 
Society and French Society of Emergency Medicine. Ann Intensive Care. 2019;9(1):105.

5. Le GJ, Boumendil A, Guidet B, Corvol A, Saint-Jean O, Somme D. Are elderly patients' opinions sought before admission to an intensive care unit? Results of the ICE-CUB study. Age Ageing. 2016;45(2):303-9.

6. Cohen S, Sprung C, Sjokvist P, Lippert A, Ricou Bm Baras M, et al. Communication of end-of-life decisions in European intensive care units. Intensive Care Med. 2005;31(9):1215-21.

7. Heyland DK, Barwich D, Pichora D, Dodek P, Lamontagne F, You JL, et al. Failure to engage hospitalized elderly patients and their families in advance care planning. JAMA Intern Med. 2013;173(9):778-87.

8. Gjerberg E, Lillemoen L, Forde R, Pedersen R. End-of-life care communications and shared decision-making in Norwegian nursing homesexperiences and perspectives of patients and relatives. BMC Geriatr. 2015;15:103.

9. Piers RD, Azoulay E, Ricou B, Ganz FD, Decruyenaere J, Max A, et al. Perceptions of appropriateness of care among European and Israeli intensive care unit nurses and physicians. JAMA. 2011;306(24):2694-703.

10. Benoit DD, Jensen HI, Malmgren J, Metaxa V, Reyners AK, Darmon M, et al. Outcome in patients perceived as receiving excessive care across different ethical climates: a prospective study in 68 intensive care units in Europe and the USA. Intensive Care Med. 2018;44(7):1039-49.

11. Wilson ME, Dobler CC, Zubek L, Gajic O, Talmor D, Curtis JR, et al. Prevalence of disagreement about appropriateness of treatment between ICU patients/surrogates and clinicians. Chest. 2019;155(6):1140-7.

12. Gonella S, Basso I, Dimonte V, Martin B, Berchialla P, Campagna S, et al. Association between end-of-life conversations in nursing homes and end-of-life care outcomes: a systematic review and meta-analysis. J Am Med Dir Assoc. 2019;20(3):249-61.

13. Detering KM, Hancock AD, Reade MC, Silvester W. The impact of advance care planning on end of life care in elderly patients: randomised controlled trial. BMJ. 2010;340:C1345.

14. Hospitaladministration 2020. COVID-19 admission and treatment. https:// infonet.regionsyddanmark.dk/?DokID=772599. Accessed 6 May 2021.

15. Danish Patient Safety Authority. Guideline regarding deselection and withdrawal of life-sustaining treatment. Available at: https://www.retsi nformation.dk/eli/retsinfo/2019/9935. Accessed 6 May 2021.

16. Danish Patient Safety Authority. Guideline regarding resuscitation and deselection of resuscutation. Available at: https://www.retsinformation. dk/eli/retsinfo/2019/9934. Accessed 6 May 2021.

17. Nissen SK, Fournaise A, Lauridsen JT, Ryg J, Nickel CH, Gudex C, et al. Cross-sectoral inter-rater reliability of the clinical frailty scale - a Danish translation and validation study. BMC Geriatr. 2020;20(1):443.

18. Statens Serum Institut (SSI). Focus report: nursing homes. Available at: https://www.ssi.dk/-/media/arkiv/subsites/covid19/fokusrapporter/covid 19-p-plejehjem-fokusrapport-30092021.pdf?la=da Accessed 10 Nov 2021

19. Statistikbanken. RESI01. Available at: https://www.statistikbanken.dk/ statbank5a/SelectVarVal/Define.asp?Maintable $=$ RESI01\&PLanguage $=0$ Accessed 10 Nov 2021.

20. Williams S, Hwang K, Watt J, Batchelor F, Gerber K, Hayes B, et al. How are older people's care preferences documented towards the end of life? Collegian. 2020;27(3):313-8.

21. Kompanje EJ, Piers RD, Benoit DD. Causes and consequences of disproportionate care in intensive care medicine. Curr Opin Crit Care. 2013;19(6):630-5.

22. Krones T, Budilivschi A, Karzig I, Otto T, Valeri F, Biller-Andorno N, et al. Advance care planning for the severely ill in the hospital: a randomized trial. BMJ Support Palliat Care. 2019. https://doi.org/10.1136/bmjsp care-2017-001489.

23. Zhang B, Wright AA, Huskamp HA, Nilsson ME, Maciejewski ML, Earle CC, et al. Health care costs in the last week of life: associations with end-of-life conversations. Arch Intern Med. 2009;169(5):480-8.

24. Neergaard MA, Skorstengaard MH, Brogaard T, Bendstrup E, Lokke A Aagaard S, et al. Advance care planning and longer survival in the terminally ill: a randomised controlled trial unexpected finding. BMJ Support Palliat Care. 2020;10(2):221-2.

25. Waller A, Sanson-Fisher R, Nair BRK, Evans T. Are older and seriously ill inpatients planning ahead for future medical care? BMC Geriatr. 2019:19:212.
26. Brighton LJ, Bristowe K. Communication in palliative care: talking about the end of life, before the end of life. Postgrad Med J. 2016:92(1090):466-70.

27. Wright AA, Zhang B, Ray A, Mack JW, Trice E, Balboni T, et al. Associations between end-of-life discussions, patient mental health, medical care near death, and caregiver bereavement adjustment. JAMA. 2008;300(14):1665-73.

28. Carson SS, Cox CE, Wallenstein S, Hanson LC, Danis M, Tulsky JA, et al. Effect of palliative care-led meetings for families of patients with chronic critical illness: a randomized clinical trial. JAMA. 2016;316(1):51-62.

29. Lamas DJ, Owens RL, Nace RN, Massaro AF, Pertsch NJ, Moore ST, et al. Conversations about goals and values are feasible and acceptable in long-term acute care hospitals: a pilot study. J Palliat Med. 2017;20(7):710-5.

30. Alqahtani AJ, Mitchell G. End-of-life care challenges from staff viewpoints in emergency departments: systematic review. Healthcare (Basel). 2019;7(3):83.

31. Larson DG, Tobin DR. End-of-life conversations: evolving practice and theory. JAMA. 2000;284(12):1573-8.

32. Lakin JR, Block SD, Billings JA, Koritsanszky LA, Cunningham R, Wichmann $L$, et al. Improving communication about serious illness in primary care: a review. JAMA Intern Med. 2016;176(9):1380-7.

33. Travers A, Taylor $\mathrm{V}$. What are the barriers to initiating end-of-life conversations with patients in the last year of life? Int J Palliat Nurs. 2016;22(9):454-62.

34. Downar J, Goldman R, Pinto R, Englesakis M, Adhikari NK. The "surprise question" for predicting death in seriously ill patients: a systematic review and meta-analysis. CMAJ. 2017;189(13):E484-93.

35. Highet G, Crawford D, Murray SA, Boyd K. Development and evaluation of the supportive and palliative care indicators tool (SPICT): a mixedmethods study. BMJ Support Palliat Care. 2014:4(3):285-90.

36. Fritz Z, Slowther AM, Perkins GD. Resuscitation policy should focus on the patient, not the decision. BMJ. 2017:356:1813.

37. Mack DS, Dosa D. Improving advanced care planning through physician orders for life-sustaining treatment (POLST) expansion across the united states: lessons learned from state-based developments. Am J Hosp Palliat Care. 2020;37(1):19-26.

38. Jimenez G, Tan WS, Virk AK, Low CK, Car J, Ho AHY. Overview of systematic reviews of advance care planning: summary of evidence and global lessons. J Pain Symptom Manag. 2018;56(3):436-59.e25.

39. Hurlow A, Wyld L, Breen A. An evaluation of advance care planning during the COVID-19 pandemic: a retrospective review of patient involvement in decision making using routinely collected data from digital ReSPECT records. Clin Med. 2021;21(4):e395-8.

40. Comer AR, Hickman SE, Slaven JE, Monahan PO, Sachs GA, Wocial LD, et al. Assessment of discordance between surrogate care goals and medical treatment provided to older adults with serious illness. JAMA Netw Open. 2020;3(5):e205179.

41. Swenson A, Hyde R. Understanding patients'end-of-life goals of care in the emergency department. J Am Coll Emerg Physicians Open. 2021:2(2):e12388

42. The WHO Rapid Evidence Appraisal for COVID-19 Therapies (REACT) Working Group. Association between administration of systemic corticosteroids and mortality among critically ill patients with COVID-19: a meta-analysis. JAMA. 2020;324(13):1330-41.

43. Bergenholtz H, Missel M, Timm H. Talking about death and dying in a hospital setting - a qualitative study of the wishes for end-of-life conversations from the perspective of patients and spouses. BMC Palliat Care. 2020;19(1):168

44. Simon J, Porterfield P, Bouchal SR, Heyland D. "Not yet" and "Just ask": barriers and facilitators to advance care planning-a qualitative descriptive study of the perspectives of seriously ill, older patients and their families. BMJ Support Palliat Care. 2015;5(1):54-62.

\section{Publisher's Note}

Springer Nature remains neutral with regard to jurisdictional claims in published maps and institutional affiliations. 